\title{
A enfermagem no Brasil no contexto da força de trabalho em saúde: perfil e legislação
}

\author{
Nursing in Brazil in the context of the work force of the health: profile and legislation \\ La enfermería en Brasil en el contexto de la fuerza de trabajo en salud: perfil y legislación
}

\author{
Maria José Bistafa Pereira', Cinira Magali Fortuna', \\ Silvana Martins Mishima', Maria Cecília Puntel de Almeida', Silvana Matumoto' \\ 'Universidade de São Paulo. Escola de Enfermagem de Ribeirão Preto. \\ Departamento de Enfermagem Materno-Infantil. Ribeirão Preto, SP
}

Submissão: 12/12/2008

Aprovação: 3 1/08/2009

\section{RESUMO}

Este artigo parte da referência da enfermagem como prática social, apóia-se na categoria trabalho para abordar a força de trabalho em enfermagem no Brasil. Resgata historicamente a conformação do seu perfil vinculada à organização mais geral do setor saúde do país. $\mathrm{O}$ perfil do trabalhador relaciona-se à finalidade que se imprime ao processo de trabalho em saúde. Entendemos Que as forças em movimento no contexto da saúde são contingenciadas, mas Que seus atores organizados podem imprimir direções determinadas pelo âmbito técnico, ético e político. Lançamos o convite para a reflexão sobre Quais perfis de enfermagem defendemos e Queremos para os múltiplos Brasis. Destacamos características do trabalhador de enfermagem generalista, assinalando Que para esta formação serão necessários novos arranjos de poderes e saberes Que poderão construir outros perfis e contornos para o trabalho em saúde e para a enfermagem, de forma mais comprometida com os princípios do Sistema Único de Saúde.

Descritores: Enfermagem; Conhecimentos atitudes e práticas em saúde; Força de trabalho, Enfermagem em saúde pública.

\section{ABSTRACT}

This article approaches nursing as a social practice, grounded in the work category to address the nursing work force in Brazil. It recovers the historical arrangement of its profile associated to the most general organization of the health sector in the country. Workers' profile is related to the aim of the health work process. Authors understand that the moving forces in the health context are restricted, but its organized actors can give directions determined by the technical, ethical and political ambits. Readers are invited to reflect on which nursing profiles are supported and targeted to the multiple Brazils. The characteristics of generalist nursing workers are highlighted, evidencing that new power and knowledge arrangements will be necessary for this training. This can build other profiles and outlines to health work and nursing, more committed with the principles of the Unified Health System.

Descriptors: Nursing; Health knowledge, attitudes, practice; Labor force, Public health nursing

\section{RESUMEN}

Este artículo parte de la referencia de la enfermería como práctica social, se apoya en la categoría trabajo para tratar la fuerza de trabajo en enfermería en Brasil. Rescata históricamente la conformación de su perfil vinculada a la organización más general del sector de salud. El perfil del trabajador se relaciona a la finalidad del proceso de trabajo en salud. Entendemos que las fuerzas en movimiento en el contexto de salud son restrictas, pero Que sus actores organizados pueden imprimir direcciones determinadas por el ámbito técnico, ético y político. Convidamos para reflexionar sobre cuales perfiles de enfermería defendemos y queremos para los múltiplos Brasiles. Destacamos características del trabajador de enfermería generalista, señalando Que para esa formación serán necesarios nuevos arreglos de poderes y saberes Que podrán construir otros perfiles y contornos para el trabajo en salud y para la enfermería, más comprometidos con los principios del Sistema Único de Salud.

Descriptores: Enfermería; Conocimientos, actitudes y práctica en salud; Fuerza de trabajo, Enfermería en salud pública. 


\section{INTRODUÇÃO}

Na discussão sobre a enfermagem no Brasil, no âmbito da força de trabalho em saúde, é necessário que se demarque alguns pontos para a reflexão Que aQui se propõe: a enfermagem como prática social, ou seja, enfermagem como trabalho, cuja compreensão se dá pela inserção em um dado contexto; e o Que entendemos como força de trabalho e perfil profissional esperado para o contexto atual Que conforma a necessidade de atenção integral.

Ao anunciarmos a enfermagem enquanto trabalho, estamos nos fundamentando em uma concepção Que a toma para além de uma profissão com competência técnica científica.

Trabalho é designado como uma atividade Que altera o estado da natural (da natureza), transformando-o para melhor atender necessidades ${ }^{(1)}$. No caso do trabalho humano, este é marcado pela intencionalidade e pala socialidade. Com isso, antes da realização do produto final, o homem imagina/desenha o que produzir. Em síntese, o trabalho sempre é uma ação transformadora intencional.

A incorporação da categoria trabalho na análise das práticas de saúde possibilita a compreensão de Que estas práticas são determinadas pela finalidade social do trabalho. Esta (finalidade) refere-se a um projeto de ação Que traduz uma dada concepção de processo saúde - doença e cuidado. Por exemplo, a partir de uma perspectiva biológica e multicausal, a finalidade do processo de trabalho em saúde pode ser a restauração da normatividade biomédica, eneuanto que da perspectiva coletiva - psicossocial, cultural, biológica -, a finalidade poderá ser a promoção da saúde e a emancipação dos sujeitos ${ }^{(2)}$.

Neste processo de trabalho sempre teremos "algo" (indivíduo com algum problema, uma comunidade enfrentando determinadas dificuldades) para ser transformado. Para operar essa transformação serão necessários distintos instrumentos (materiais, saberes, força de trabalho) a serem manipulados por diferentes agentes/ trabalhadores. Ao operar esses instrumentos cada agente/ trabalhador também imprime sua conformação (subjetividade, desejos) no uso desses instrumentos no processo de trabalho ${ }^{(3)}$.

Ao adotarmos o referencial da categoria trabalho para a enfermagem estamos tomando-a como uma prática social, ou seja, entendemos Que a enfermagem estabelece relações com outros trabalhos, com as dimensões econômicas, culturais e sociais das instâncias Que compõem a estrutura de uma sociedade. Desta forma, a enfermagem enQuanto uma prática de saúde é conformada por essa teia das relações sociais. Por outro lado, também contribui para conformação das outras práticas sociais. Portanto, essa enfermagem está num contexto socio-histórico sobre o Qual interfere e sofre interferências, não é neutra, ou seja, se conforma nele ao mesmo tempo em Que o conforma.

Nesta perspectiva, entendemos Que a prática de enfermagem é heterogênea nas diversas sociedades em cada momento histórico. Em cada contexto onde esta prática se desenvolve, ela vai adeuirindo feições e características próprias, no atendimento das necessidades de saúde, Que são reconhecidas pelo projeto Que se busca conformar ou está conformado.

Esse olhar requer re-investir nas discussões sobre a enfermagem a partir de sua complexidade, as relações Que estabelece com outros conhecimentos e práticas, e não tomá-la de forma linear e com caráter estritamente técnico. Ainda, é importante Que ao tomar a enfermagem nesta dimensão, esta apreensão será sempre parcial. Portanto, estamos assinalando Que levantaremos interrogações mais Que "respostas". Acreditamos, Que essas respostas serão construídas em interlocução Que busca a complementaridade pela diferença, lembrando que os contrários constituem componentes essenciais na totalidade.

Outro conceito que consideramos de importância refere-se ao de força de trabalho. Ao falarmos sobre força de trabalho estamos considerando o trabalhador de saúde numa relação produtiva, promovendo uma transformação no caso, indivíduo com algum problema, uma comunidade enfrentando determinadas dificuldades, para ser transformado. Esse trabalhador não é visto como mais um insumo, no conjunto dos insumos necessários para desenvolvimento do trabalho, mas como um agente Que detém potência para operar a transformação pretendida.

A força de trabalho em enfermagem apresenta valores distintos no conjunto dos trabalhadores produzindo diferentes status/ reconhecimento nas diversas categorias profissionais. Isso não é determinado por legislações verticais ou por vontades das categorias e entidades de classe.

Evidenciamos desta forma Que há uma divisão técnica e social do trabalho e que a depender do contexto, temos uma dada composição da força de trabalho e da sua expressão enQuanto fazer/saber, expressão em números de profissionais, em postos de trabalho, em estratificação das categorias. Assim a enfermagem é determinada e também determina, e conforma sua história no Brasil na conjuntura das políticas de saúde.

Os conceitos aQui apresentados também vão apontando o Que estamos tomando por perfil. Reconhecemos a importância e necessidade de abordagem de perfil de recursos humanos enfocando sexo, idade, nível de escolaridade, inserção em postos de trabalho, distribuição geográfica no país, distribuição por tipo de serviço, no entanto, vamos aqui nos pautar no enfoque da dimensão mais voltada para a finalidade da produção do trabalho em saúde. Aqui vamos demarcando Que estamos comprometidas com o desenvolvimento de uma prática de enfermagem Que busque desenvolver intervenções no cotidiano com possibilidades de operar os serviços de saúde de forma a estabelecer uma relação diferenciada do trabalhador de saúde/usuário, relação acolhedora; marcada pelo compromisso e responsabilização pela saúde dos usuários. Também, pela preocupação com o desenvolvimento da autonomia do usuário, visando Que este vá se apropriando de diversas tecnologias, Que cada vez mais resolva ou minimize parte dauilo que lhe tem causado sofrimento. Sabemos Que em nosso país as transformações das práticas de saúde são demarcadas por determinantes econômicos, políticos e sociais, de âmbito nacional e internacional ${ }^{(4)}$.

Não se trata, nesta produção de recuperar a construção dos modelos de atenção à saúde no Brasil, no entanto para melhor compreender essas idéias vamos tomar o Sistema Único de Saúde como um demarcador da história das políticas de saúde.

\section{A ENFERMAGEM NO BRASIL NAS DÉCADAS DE 1970/ 1980 - PERFIL E LEGISLAÇÃO}

A constituição da força de trabalho em enfermagem terá e será a expressão das necessidades e dos interesses sócio-políticos e econômicos dessa conjuntura. 
Assim, o Brasil, diga-se de passagem, Que não desconsideramos os muitos brasis, na década de setenta enfrentou um momento político de ditadura militar, estando em curso o "milagre econômico" e havendo uma estrutura de atenção à saúde excludente e destinado a Quem detinha carteira de trabalho assinada ou podia pagar pelos serviços.

Nesse período da história, as políticas de saúde articuladas a Projetos hegemônicos da sociedade conformaram um modelo de atenção onde as ações de saúde pública estavam separadas das ações curativas individuais. Havia em curso o sucateamento das ações de prevenção, acompanhada da deterioração das condições de acesso a saneamento básico, trabalho, renda, entre outros.

Fortalecia-se o modelo assistencial médico privatista centrado no saber unidirecionalmente biomédico, na atenção hospitalar, curativa e individual, marcado por processos de trabalho fragmentados e centrados em procedimentos. $\mathrm{O}$ interesse a ser preservado pela saúde era a recuperação do corpo dos trabalhadores com a finalidade de garantir a produção e a acumulação do capital.

Neste contexto, a enfermagem respondia e conformava-se nessas condições: concentrando-se no âmbito dos serviços privados e hospitalares (especialmente a mão de obra não Qualificada Que aumentava a lucratividade desses estabelecimentos).

A atenção médica individual aos trabalhadores urbanos já vinha em curso desde a década de 20, com a Lei Eloy Chaves de 1923, regulamentando as Caixas de Pensões e Aposentadorias (CAPs), seguidas dos Institutos de Pensões e Aposentadorias (década de 30) Que se unificaram em 1966 para a formação do Instituto Nacional de Previdência Social (INPS).

Na década de 70, ganham espaços os planos privados de atenção médica Que passam a realizar convênios com as empresas e com o Estado para ofertar a atenção médica individual para trabalhadores.

Com o processo de urbanização e com a hospitalização dos partos vamos ter uma redução do número de parteiras no país.

Particularmente, no final da década de setenta, para a enfermagem vai ocorrer aumento das vagas para a formação universitária o Que não aconteceu com os demais cursos da área da saúde.

Segundo Medici e Paim ${ }^{(5)}$, as explicações para o aumento desses trabalhadores foram: no plano político e econômico do pós-64; incorpora-se a atenção em saúde como forma de responder as demandas sociais reprimidas, diminuindo as tensões sociais. A instalação da medicina previdenciária conveniada (como diretriz política) estabeleceu uma demanda efetiva para o setor saúde e nesse sentido as possibilidades de postos de trabalho aumentaram.

Os autores acima afirmam Que as categorias de enfermagem coneuistaram maior aumento segundo os dados apresentados pela Escola Nacional de Saúde Pública, passando de $45 \%$ entre os profissionais de saúde para mais de $51 \%$ em 1980.

Nas décadas de 70 e 80 os enfermeiros realizavam atividades mais voltadas para a supervisão, administração e controle. No plano assistencial o trabalho da enfermagem, se dá de forma a subsidiar a atenção médica. Isso se relaciona a divisão técnica e social do trabalho cabendo a esse agente o fazer intelectivo e aos demais trabalhadores os fazeres técnico e de assistência direta.

Um contingente maior de pessoal de enfermagem no setor público, mais especificamente de enfermeiros e auxiliares de enfermagem é verificado. Há um crescimento da absorção de pessoal no setor público, sendo uma das possíveis explicações a instalação da crise econômica tanto no Brasil (fim do milagre econômico) como no mundo, decorrente da crise do petróleo, e mais uma vez a oferta dos serviços de saúde se apresenta como recursos para atender demandas reprimidas e diminuidores das tensões sociais.

Já no final da década de 1970, se instala uma crise mundial no mundo capitalista e o contexto se caracteriza pela restrição das políticas sociais frente à redução do financiamento gerado pela crise econômica recessiva, e consequentemente tem-se aumento do desemprego, arrocho salarial, deteriorização das condições de vida da maioria da população, condições essas que geram maior demanda para os serviços de saúde pública. Lembrando que o modelo hegemônico é de alto custo operacional, portanto adverso a situação de crise econômica, tal situação leva a Organização Mundial da Saúde a convocar a Conferência Internacional de Alma Ata, em 1978 com o tema central Cuidados Primários à Saúde ${ }^{(6)}$.

O Brasil, além de sofrer os reflexos desta crise internacional também apresentava suas características próprias. Esta não se limitava ao desequilíbrio entre receita e despesa, mas, emergia de uma série de ações políticas, caracterizadas fortemente pelo desemprego crescente, redução do valor real dos salários, fraudes contra o sistema previdenciário, facilitadas pela forma de financiamento adotada; baixa cobertura assistencial do setor público estadual e municipal; custos crescentes da assistência médica pela incorporação de novas tecnologias; bem como um modelo de saúde dominante pautado na assistência médica individual e curativa.

Esse processo promove enfraquecimento no poder político, e neste contexto, o movimento pela redemocratização do país se fortalece, e particularmente no setor saúde também se consolida o movimento da reforma sanitária Que culmina com criação do Sistema Único de Saúde, Quando pela primeira vez se coneuista um capítulo na Carta Magna Brasileira, específico para a Saúde.

Desta forma fica estabelecido na Constituição Brasileira ${ }^{(7)}$, em 1988, Que Saúde é direito do cidadão e dever do Estado, elegendo a cidadania e a dignidade da pessoa humana como fundamentais.

A regulamentação do SUS se deu por meio das Leis Orgânicas da Saúde 8080/90 e 8142/90, onde se encontra descrito os princípios do SUS entre eles: a universalização do atendimento, a integralidade da atenção, a equidade, a participação social e entre os organizativos destacamos a descentralização, Que permitiu instituir a responsabilidade da organização do sistema local de saúde ao município.

Esta decisão política foi possibilitando a transferência gradativa de responsabilidades, na prestação de assistência à saúde da população, principalmente, no planejamento e organização da rede de atendimento primário, com a unificação das unidades básicas de saúde, sob o comando municipal.

O processo de municipalização foi se conformando e neste movimento a rede básica municipal vai sendo implantada de forma bastante considerável.

Os princípios norteadores do SUS, definidos na Lei Orgânica da Saúde 8080/90, estabelecem a conformação de um modelo de atenção Que se paute pela integralidade da atenção pressupondo Que as necessidades precisam ser desvendadas em suas múltiplas dimensões considerando a diversidade e complexidade das mesmas frente às relações materiais de existência dos usuários. 
Ainda, define que o Sistema de Saúde, precisa trabalhar de forma integral e integrada, a partir do reconhecimento da necessidade do usuário e identificação do tipo de intervenção, e desta forma o sistema precisa ter serviços disponíveis em seus vários níveis de atenção: primário, secundário e terciário possibilitando o acesso de forma integrada.

Outra característica necessária na reversão do Modelo Assistencial comprometido com o SUS é a indissociabilidade entre as ações preventivas, curativas, promocionais e reabilitadoras.

Este processo imprime outras possibilidades, como também outras exigências para os trabalhadores dos serviços de saúde. O SUS se constitui em um protejo tecno-político Que carrega novos valores e enfoques teóricos na produção da saúde, exigindo novos perfis profissionais.

\section{A ENFERMAGEM NO BRASIL NAS DÉCADAS DE $1990 \mathrm{E}$ 2000 - PERFIL E LEGISLAÇÃO}

Na década de 90 o Sistema Único de Saúde (SUS), como já apontado passa a ser operacionalizado a partir das leis orgânicas da saúde (8080/90 e 8142/90). Paradoxalmente, vamos ver desenhado na conjuntura mundial a expansão das políticas neoliberais. Há um afastamento do Estado das Políticas Sociais o Que fará "breques e descompassos" em nosso país na operacionalização dos ditames Constitucionais de Que a Saúde é Direito de todos e Dever do Estado.

Mesmo assim, demarcamos um período de expansão da rede ambulatorial em todo o país com a criação das Unidades Básicas de Saúde, ambulatórios Regionais, hospitais secundários e terciários.

No período de 1980 a 2002, pode-se verificar um alto incremento dos estabelecimentos públicos, principalmente na esfera municipal, demarcando uma significativa expansão do acesso da população aos serviços de saúde com a implantação do SUS. Assim, pode-se afirmar Que o processo de municipalização cria a expansão de postos de trabalho nas Secretarias Municipais de Saúde de todo o país, na atenção básica.

Também é possível verificar a distribuição para o período de 1980 a 2002 dos empregos totais no setor público e privado, assim como os empregos nos níveis federal, estadual e municipal, além da distribuição por nível de formação e por categoria profissional.

Pode-se verificar Que para o período de 1980 a 2002, houve uma ambulatorização do trabalho em saúde e também da enfermagem, e ainda a inserção de outros trabalhadores como os Agentes Comunitários de Saúde ${ }^{(8)}$.

Em 1991, o Ministério da Saúde lança no Programa de Agentes Comunitários de Saúde, sendo Que gradativamente um grande contingente de trabalhadores foi incluído na força de trabalho em saúde.

O projeto Que anunciamos da produção de cuidados integrais em uma rede Que tome a saúde de Qualidade como direito de todo cidadão, encontra sustentação nas leis Que vêm conformando as políticas de saúde. Seria impossível tratar das inúmeras legislações Que conformam o modelo assistencial do SUS, de formação dos trabalhadores de saúde e, ainda da regulação do trabalho deste setor, em especial da enfermagem, portanto faremos recortes da legislação Que evidenciam a necessidade do perfil dos trabalhadores de saúde, onde se encontram os da enfermagem.

Anteriormente, citamos a Constituição Brasileira e as Leis Orgânicas da Saúde, Que consideramos coneuistas fundamentais nesse processo de implantação do SUS. Na luta pela consolidação do SUS, vamos viver conQuistas e retrocessos. Em relação as conquistas legais pode-se atribuir certo destaque ao setor, dentro do campo das políticas públicas, pela sua capacidade de se reorganizar e ainda ser o Que mais avançou nos aspectos relativos à legislação(9).

Dentre esta legislação destacamos a portaria 648/GM de $2006^{(10)}$ Que trata da Política Nacional de Atenção Básica, produto da revisão de edições anteriores e se fez necessário proceder adeQuações tendo em vista as transformações presentes no processo de desenvolvimento da Atenção Básica $(A B)$ do país. A portaria destaca Que a $A B$ deve ser orientada pelos princípios da universalidade, acessibilidade, coordenação do cuidado, vínculo e continuidade, integralidade, responsabilização, humanização, eqüidade e participação social. A atenção básica se caracteriza por ações individuais e coletivas desenvolvidas articuladamente com uma prática gerencial participativa e democrática, com o enfoque no trabalho de equipe, considerando o contexto onde as populações vivem.

Convém destacar um aspecto dessa portaria Que a diferencia de outros documentos legais em relação ao SUS, pois acrescenta a dimensão da singularidade dos sujeitos Que buscam atenção, da complexidade para a atenção.

A Política Nacional de Atenção Básica, encontra-se articulada à Portaria 399/GM, de 22 de fevereiro de $2006^{(11)}$, Que trata do Pacto pela Saúde, editada pelo Ministério da Saúde e Que confirma os princípios e as diretrizes do SUS como eixo estruturante da Política de Saúde brasileira.

O Pacto pela Saúde é constituído de três componentes Que se complementam e se articulam: o Pacto pela Vida, o Pacto de Gestão e o Pacto em Defesa do SUS.

No conjunto, apresentam mudanças operacionais no sentido de efetivar acordos nas três esferas de gestão do SUS, tendo em vista inovar processos e instrumentos de gestão, redefinir as responsabilidades coletivas por resultados sanitários, pautando-se pelas necessidades da população e de promover a Qualidade social e sanitária à população. A seguir traremos diretrizes operacionais específicas de cada um desses componentes, visando construir a imagem objetiva do trabalho em saúde e particularmente da enfermagem.

O Pacto pela Vida estabelece seis prioridades, a partir da análise da situação de saúde brasileira, sendo elas: Saúde do Idoso; Controle do câncer do colo do útero e da mama; Redução da mortalidade infantil e materna; Fortalecimento da capacidade de resposta às doenças emergentes e endemias, com ênfase na dengue, hanseníase, tuberculose, malária e influenza; Promoção da Saúde e Fortalecimento da Atenção Básica. Define Que os estados, regiões e municípios devem pactuar ações necessárias alcançar metas e objetivos frente às prioridades estabelecidas para a atenção à saúde.

As prioridades elencadas reforçam a necessidade de (re)pensarmos o trabalho em saúde e em particular o da enfermagem fundamentado no princípio da integralidade da atenção, considerando a indivisibilidade das dimensões constituintes do ser humano - pessoas Que assistimos, como também a indivisibilidade das ações promoção, proteção e recuperação da saúde e a 
integração dos serviços Que compõem o Sistema de Saúde. Essas premissas devem nortear o trabalho da enfermagem em todos os níveis de atenção. A necessidade de desempenhar o trabalhar em equipe aqui está posto, como também de desenvolvermos conhecimento, habilidades e atitudes, articuladas e integradas para o cuidado individual, coletivo e de gestão participativa.

Outro componente do Pacto da Saúde é o Pacto de Gestão que fundamentalmente reafirma o processo de descentralização devendo este se dar por meio da regionalização. Define as funções e responsabilidades sanitárias de cada esfera - Ministério propositor, e as Comissões Intergestoras Bi e Tripartite instâncias de pactuação e de deliberação.

As diretrizes e os princípios orientadores do processo de regulação da atenção à saúde e regulação assistencial estão previstos nesta portaria. Ainda podemos identificar o estabelecimento de ações de participação e controle social, as diretrizes da gestão, da educação em saúde e a definição do financiamento do SUS, pelas três esferas de governo definindo blocos de financiamento para a atenção básica, atenção de média e alta complexidade, vigilância em saúde, assistência farmacêutica e para a gestão.

Este se constitui em mais um instrumento de trabalho Que exige dos gestores e trabalhadores dos serviços de saúde articular saberes das diversas áreas do conhecimento e, portanto remete mais uma vez a necessidade do trabalho de equipe numa perspectiva da interdisciplinaridade ${ }^{(12)}$ para Que possamos caminhar para uma atenção integral.

O terceiro componente do Pacto da Saúde é o Pacto em Defesa do SUS, Que busca assegurar a retomada da (re)politização da saúde, comprometida com a defesa do caráter público e universal do Sistema de Saúde do Brasil.

Ao olharmos para a chamada deste componente fica evidente Que o planejamento, a mobilização social e mediar encontros entre trabalhadores e entre estes e população e entre estes e usuários serão componentes do trabalho, também da enfermagem. Conhecer legislação da saúde de âmbito nacional e local e obviamente especifica da profissão é imprescindível para o perfil do trabalhador de enfermagem para fortalecer o projeto Que defendemos.

A Norma Operacional Básica do Sistema Único de Saúde - NOBRH - (13) Que enfatiza a importância do trabalho, a necessidade da valorização dos profissionais na implantação dos modelos assistenciais e regulação das relações de trabalho no setor saúde, é uma das conquistas e mais um recurso legal para instrumentalizar a operacionalização dos preceitos do SUS, no âmbito dos recursos humanos, Que nunca havia sido objeto de Normas Operacionais Básicas.

Diante do contexto apresentado e da conformação sóciohistórica, a enfermagem assume expressões múltiplas: podemos falar em muitas enfermagens. A legislação da saúde e da própria enfermagem aglutina e materializa movimentos, lutas, disputas.

Então, lançamos o convite para refletirmos sobre Quais perfis de enfermagem defendemos e Queremos para a enfermagem brasileira em seus múltiplos Brasis. São apostas Que serão contingenciadas pelas forças em movimento, mas Que seus atores organizados podem imprimir direções determinadas pelo âmbito técnico, ético e político

Esses aspectos colocam para a enfermagem o desafio da construção de uma prática Que de certo modo faz tensionamentos entre o Que se faz hegemonicamente e a mudança pretendida nos modos de operar, pesquisar, cuidar, ensinar.

A cisão entre atenção individual curativa tendo o hospital como principal cenário precisa ser revisitada. Ainda, as práticas preventivas de caráter coletivo até então presentes nas práticas de saúde pública também precisam ser repensadas. Um grande desafio, portanto, é romper com as dicotomias construídas social e historicamente: curativo e preventivo, hospital e saúde pública, cuidar e gerenciar, ensinar e fazer, pesQuisar e ensinar, universidade e serviço, teoria e prática, dentre outras.

Outro conceito a ser trabalhado e operacionalizado é o da complexidade na simplicidade. Se continuarmos tomando a complexidade como sinônimo de saber operar equipamentos e técnicas sofisticados, de maior poder diagnóstico e de intervenção manteremos a valorização apenas de procedimentos. O desafio passa por re-construir Que a complexidade está em todos os atos de cuidar e em todos os níveis de atenção dada a própria natureza da vida e das suas expressões em saúde/doença: há uma complexidade em se construir a integralidade.

A diversidade e a complexidade das necessidades geradas nas relações materiais da existência humana precisam ser desvendadas e trabalhadas em suas múltiplas dimensões, o que implica assumir a complexidade do conceito teórico e operacional de necessidades.

Nesta perspectiva, pressupõe-se contar com trabalhadores com uma concepção ampliada do processo saúde-doença-cuidado, possibilitando desta forma, desenvolver uma prática mais integral e integrada, o que implica também em dispor ou lutar por se ter uma rede de atenção com acesso aos níveis de atenção primário, secundário e terciário, além de equipamentos intersetoriais.

Desafia-nos a capacidade de considerar a singularidade das famílias e das pessoas para o enfrentamento dos processos de saúdedoença. Sabemos melhor ainda cumprir normas à priori Que massificam as ações.

Outro desafio para a enfermagem é a inserção em outra perspectiva no trabalho em equipe. Essa inserção pressupõe horizontalizações. Nossa história traduz-se em uma posição hierarquizada e rígida: enfermeiros - técnicos - auxiliares atendentes - agentes comunitários de saúde. Ao mesmo tempo, posição subalternizada aos demais trabalhadores, especialmente ao médico.

O desafio supõe a construção do trabalho em equipe-interação conforme define Peduzzi ${ }^{(14)}$. Nessa, seus agentes desenvolvem ações por meio da interação de práticas e de saberes, superando a equipe agrupamento em Que os agentes e saberes estão em um mesmo serviço, mas não constroem processos coletivos de cuidar.

O trabalho em equipe pressupõe ainda a consideração da subjetividade e produção do trabalhador no trabalho. No trabalho em saúde, seus agentes vão se constituindo: seus modos de pensar, ser, fazer, amar, estão em produção nesse trabalho de encontros e desencontros.

Assinalamos como desafio a re-significação do trabalho em equipe, em geral revestido de uma busca por harmonia e apagamento das diferenças: uma mesma língua, um mesmo objetivo, o vestir da camisa. Consideramos o trabalho em equipe como complexidade de relações afetivas, de poderes, de saberes Que serão ora conflituosas, ora harmônicas, mas Que movimentam atores, projetos e disputas. Esses processos conflitivos podem ganhar visibilidade e se enfrentados, repactuados podem vir a colocar o trabalho na direção de sua finalidade: 
cuidar da vida dos trabalhadores e dos usuários ${ }^{(15)}$.

No conjunto de trabalhadores Que operam um serviço temos projetos individuais e projetos coletivos em disputa e em circulação, por exemplo: podemos ter uma trabalhadora da enfermagem cujo projeto individual seja o de assegurar seu salário, pagar sua faculdade e conseguir outro emprego. Esse projeto individual é real e legítimo, no entanto o trabalho não pode guiar-se exclusivamente por esse projeto: há Que tecer por horizonte o projeto institucional e os demais projetos de todos os trabalhadores e usuários.

Considerar, na medida do possível, os projetos individuais explicitando-os e rearticulando-os entre si e com projetos coletivos e institucionais nos remete a necessidade do exercício de uma prática gerencial participativa e democrática.

Estes desafios já explicitados nos impõem outra revisita reconstrução Que vai implicar em práxis: a da formação de trabalhadores de saúde e em especial de trabalhadores da enfermagem.

Está colocado na legislação tanto do SUS como nas leis e diretrizes básicas da educação a necessidade da formação de enfermeiros generalistas.

É comum ver-se considerar o profissional generalista como aquele Que sabe um pouco das especialidades. Assinalamos a necessidade de discutirmos o Que estamos tomando por generalista. Entendemos como trabalhador capaz de considerar a complexidade da vida, incorporando as múltiplas dimensões do ser humano (biológica, ética, estética, política, ecológica, espiritual, dentre outras).

O generalista integra as diversas dimensões do processo de cuidar, não se restringe as faixas etárias e aos processos epidemiológicos ou clínicos. Integra informações entre os profissionais da equipe e entre os profissionais de outras equipes para assegurar o cuidado e sua continuidade.

Para tanto, precisará desenvolver uma relação pautada por horizontalidade e escuta Que podem produzir vínculos. Essa prática desloca-se do foco na doença para aquele voltado ao sujeito.

O Que é melhor para o usuário emerge dessa relação de interação construída por ambos. Ambos partilham informações, valores, dúvidas e negociam um projeto terapêutico para o manejo dessa situação complexa ${ }^{(16)}$.

Outra característica do trabalhador generalista é o do enfoQue na família e na comunidade na elaboração do projeto de cuidado. Enfim, o trabalhador de saúde generalista necessita de formação Que se sustente em conhecimentos da semiologia, semiotécnica, da clínica, mas que também recorra a saberes da antropologia, da sociologia, da psicologia, da filosofia, das políticas de saúde, dentre outros, para não termos uma prática Que se debruça exclusivamente sobre um corpo biológico e decodificado apenas com o saber clínico.

A formação do generalista requer, portanto, o desenvolvimento de habilidades, conhecimentos e atitudes Que se voltem para o reconhecimento da singularidade dos estudantes, dos docentes inclusive nas suas limitações, dos usuários e dos serviços de saúde.

Muitos dos Que estão inseridos em trabalhos de formação sabem das dificuldades de mudanças na atual formação Que ainda separa a teoria da prática (primeiro a teoria e depois a prática em espaços de estágio), se descortina em disciplinas isoladas em Que os estudantes devem "juntar”, e se desenvolve em serviços privilegiados e situações artificiais (Hospital Escola, Centro de Saúde Escola, ambulatórios universitários e laboratórios). Esclarecemos Que não estamos negando a contribuição desses espaços - estabelecimentoescola - especialmente em dados momentos históricos pois contribuíram tanto para a formação Quanto para assistência. O Que estamos ressaltando é a inadeQuação no uso exclusivo destes na atual conjuntura em Que se Quer integrar o trabalho e a formação.

Essa exige o desafio de outra aproximação dos órgãos formadores ao SUS. A Política Nacional de Educação Permanente vem ao encontro dessas diretrizes uma vez Que se direciona para a transformação das práticas profissionais a partir da "reflexão crítica sobre as práticas reais, de profissionais reais, em ação na rede de serviços"(17).

Para tanto pressupõe Que as necessidades de saúde da população, da gestão setorial, do controle social sejam tomadas como referência de organização do trabalho, da Qualificação da prática e da formação profissional. AQui, se estabelece o Quadrilátero dos atores sociais e instituições envolvidas no setor saúde: gestão - controle social - assistência e formação para se problematizar e formular as necessidades de investimento para as transformações das práticas de saúde.

Aqui cabe um breve parêntesis, sendo Que se faz necessário esclarecer a distinção entre Educação Permanente (EP) e Educação Continuada (EC), ressaltando Que a EP tem por objetivo principal a transformação das práticas, e a EC a atualização de conhecimentos específicos, portanto a EC pode ser um dos recurso a ser utilizado pela EP, para enfrentamento dos muitos problemas identificados, em situação, não se esgotando unicamente nela.

A lei de diretrizes e bases da educação nacional no 9394/96 $6^{(18)}$ na apresentação das diretrizes Curriculares Nacionais apontam para a flexibilização curricular, processo ensino-aprendizagem centrado na realidade, diálogo entre os diferentes saberes, aberturas para processos inovadores, formação por competência, integração das disciplinas da teoria/prática e do trabalho/academia, autonomia institucional.

Em Que pesem as possibilidades de interpretações divergentes desta lei, estamos nos apoiando em pontos de fortalecimento para uma política de educação compromissada com a formação de cidadãos.

Finalizando assinalamos Que desafia-nos a construção de trabalhos coletivos e democráticos Que permitam a produção de sujeitos.

A atual conformação dos serviços de saúde e dos serviços de ensino fundamenta-se em gestões Que não consideram a organização do trabalho como espaços coletivos de aprender e de compartilhar. Produzem trabalhadores, docentes, estudantes e usuários rotinizados, fragmentados e pouco satisfeitos.

Muitas vezes a participação de trabalhadores do ensino, de saúde, de usuários e estudantes é convidada apenas para referendar posições já assumidas e assim as legitimar. A construção conjunta envolvendo de fato todos é um processo Que requer novos arranjos de poderes e de saberes Que certamente podem dar outros contornos para o trabalho em saúde e em especial para o trabalho da enfermagem. Ousemos assim rodas e redes de pactuação, de conversas e de aprenderes. 


\section{REFERÊNCIAS}

1. Santos RV. O processo histórico e social do trabalho e sua repercussão sobre a saúde. Saúde em Debate 1992; 36: 5 1-7.

2. Almeida MCP. A Classificação Internacional das Práticas de Enfermagem em Saúde Coletiva no Brasil.- CIPESC/ICN/ABEn e o processo de trabalho. In: Chianca TCM, Atunes MJM. organizadores. Classificação Internacional de Práticas de Enfermagem em Saúde Coletiva no Brasil - CIPESC/Brasil. Brasília: Associação Brasileira de Enfermagem; 1999. p. 46 -56.

3. Pereira MJB. O processo de trabalho da enfermagem na rede básica do SUS - Parte II. In: Garcia TR, Nóbrega MML organizadores. Sistemas de classificação da prática de enfermagem: um trabalho coletivo. Braślia: Associação Brasileira de Enfermagem; 2000. p.76 -82.

4. Pereira MIB, Mishima SM. Revisitando a prática assistencial: a subjetividade como matéria para a reorganização do processo de trabalho na enfermagem. Revista Interface 2003; 7: 83-100.

5. Medici AC, Paim ER. Estrutura e Dinâmica da Força de Trabalho em Enfermagem. In: Medici AC. Textos de apoio - Planejamento I: Recursos Humanos em Saúde. Rio de laneiro: Programa de Educação Continuada da Escola Nacional de Saúde Pública (PEC/ENSP) e Associação Brasileira de Pós-Graduação em Saúde Coletiva (ABRASCO); 1987. p. 124 -40.

6. Organización Mundial de la Salud. Atención Primaria de Salud - Informe de la Conferencia Internacional sobre Atención Primaria de Salud Alma-Ata. Genebra; OMS; 1978.

7. Ministério da Justiça (BR). Constituição Federal. Brasília; 1988.

8. Ministério da Saúde (BR). Glossário Temático. Normas e Manuais Técnicos. Secretaria-Executiva Gestão do Trabalho e da Educação na Saúde. Série A. Brasília: Ministério da Justiça; 2007.

9. Raggio A, Giacomini CH. A permanente Construção de Um Modelo de Saúde. Divulgação Saúde Debate 1996 dez; (16): 9-16.

10. Ministério da Saúde (BR). Portaria No 648, de 28 de março de
2006. Aprova a Política Nacional de Atenção Básica, estabelecendo a revisão de diretrizes e normas para a organização da Atenção Básica para o Programa Saúde da Família (ESF) e o Programa de Agentes Comunitários de Saúde (PACS). Brasília: Ministério da Saúde; 2006.

11. Ministério da Saúde (BR). Portaria No 399, de 22 de março de 2006. Divulga o Pacto pela Saúde 2006 - Consolidação do SUS e aprova as Diretrizes Operacionais do referido Pacto. Brasília: Ministério da Saúde; 2006.

12. Fortuna CM, Matumoto S, Pereira MIB, Mishima SM. Alguns aspectos do trabalho em saúde: Os trabalhadores e os processos de gestão. Saúde em Debate 2002; 26(62) : 272-81.

13. Ministério da Saúde (BR). Conselho Nacional de Saúde. Princípios e Diretrizes para NOB/RH. $2^{a}$ ed. Brasília: Ministério da Saúde; 2003.

14. Peduzzi M. Equipe multiprofissional de saúde: conceito e tipologia. Rev Saúde Pública 200 I; 35(1): 103-9.

15. Fortuna CM, Mishima SM, Matumoto S, Pereira MJB. O trabalho de equipe no programa de saúde da família: reflexões a partir de conceitos do processo grupal e de grupos operativos. Rev Latino-am Enfermagem 2005; I 3(2): 262-8.

16. Starfield B. Atenção primária: equilíbrio entre necessidades de saúde, serviços e tecnologia. Brasília: UNESCO / Ministério da Saúde; 2004.

17. Ministério da Saúde (BR). Política de Educação e Desenvolvimento para o SUS: Caminhos para a Educação Permanente em Saúde: Pólos de Educação Permanente em Saúde. Secretaria de Gestão do Trabalho e da Educação na Saúde. Departamento de Gestão da Educação em Saúde. Brasília; Ministério da Saúde; 2004.

18. Ministério da Educação (BR). Secretaria de Educação Fundamental. Parâmetros Curriculares Nacionais. Brasília: MEC/ SEF; 1997. 